\title{
Open Rhinoplasty Approach for Resection of a Subcutaneous Aneurysmal Fibrous Histiocytoma
}

\author{
Anna Frants, $M D^{1}$, Marissa Lafer, $M D^{1}$, Cheng $Z$ Liu, $M D^{2}$ and Judy $W$ Lee, $M D^{1^{*}}$ \\ ${ }^{1}$ Department of Otolaryngology-Head and Neck Surgery, Division of Facial Plastic and Reconstructive \\ Surgery, New York University School of Medicine, New York, USA \\ ${ }^{2}$ Department of Pathology, New York University School of Medicine, New York, USA
}

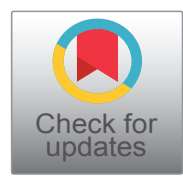

*Corresponding author: Judy W Lee, MD, Director, Department of Otolaryngology-Head and Neck Surgery, Division of Facial Plastic and Reconstructive Surgery at New York University Langone Health, 240 East $38^{\text {th }}$ St, $14^{\text {th }}$ floor, New York, NY 10016, USA, Tel: 646-501-7906

\section{Keywords}

Open rhinoplasty, Aneurysmal fibrous histiocytoma, Aneurysmal dermatofibroma, Nasal tip mass

\section{Introduction}

Aneurysmal fibrous histiocytoma (AFH), also known as aneurysmal dermatofibroma, is a rare variant of the more common and benign dermatofibroma (fibrous histiocytoma). AfHs account for approximately $2 \%$ of all cutaneous fibrous histiocytomas, and have been reported to occur most often on the extremities of young to middle aged adults, with a slight female predominance [1,2]. To our knowledge, an AFH of the face has only been reported once in the literature and was found on the forehead.

Fibrous histiocytomas are generally considered to be benign lesions, however, they have a local recurrence rate as high as $20 \%$ and a subset is also believed to have malignant potential [3-5].

Although many surgical approaches to excise cutaneous and subcutaneous lesions have been described, including Moh's micrographic surgery [4], special consideration is needed when approaching lesions in the face [6]. We will present an underutilized approach to this subcutaneous supratip lesion via an open rhinoplasty approach. The open rhinoplasty approach allowed for complete excision of the mass while simultaneously avoiding a scar in one of the most conspicuous subunits of the face.

\section{Case Report}

A 24-year-old female with a past medical history significant for asthma and Crohn's disease on adalimumab presented to the senior author's office with a painless supratip mass that fluctuated in size and had been present for 6 months despite oral antibiotics and topical steroid creams. Examination of the nose revealed a non-tender, subcutaneous, soft, smooth, raised, round mass in the right supratip region, measuring $8 \mathrm{~mm}$ in diameter. The mass appeared cystic on bimanual palpation of the right nostril and ala (Figure 1). Preoperative computed tomography (CT) with contrast was obtained to evaluate the relationship of the mass to the nasal bones. This revealed an asymmetric, enhancing soft tissue swelling of the right nasal tip measuring $8 \mathrm{~mm} \times 9 \mathrm{~mm} \times 4 \mathrm{~mm}$ (CC $\times A P \times T R)$ without involvement of the nasal bones (Figure 1). Based on imaging alone, the differential diagnosis included dermoid cyst, sebaceous hyperplasia and fibrous papule.

The mass was excised en bloc using an open rhinoplasty approach. Once the nasal skin-SMAS envelope was elevated, a lobular, cystic appearing mass was again noted in the right supratip area lateral to the upper lateral cartilage. The cephalic margin of the mass was fused onto the upper lateral cartilage and was

Citation: Frants A, Lafer M, Liu CZ, Lee JW (2019) Open Rhinoplasty Approach for Resection of a Subcutaneous Aneurysmal Fibrous Histiocytoma. J Otolaryngol Rhinol 5:067. doi.org/10.23937/25724193.1510067

Accepted: October 12, 2019: Published: October 14, 2019

Copyright: (C) 2019 Frants A, et al. This is an open-access article distributed under the terms of the Creative Commons Attribution License, which permits unrestricted use, distribution, and reproduction in any medium, provided the original author and source are credited. 


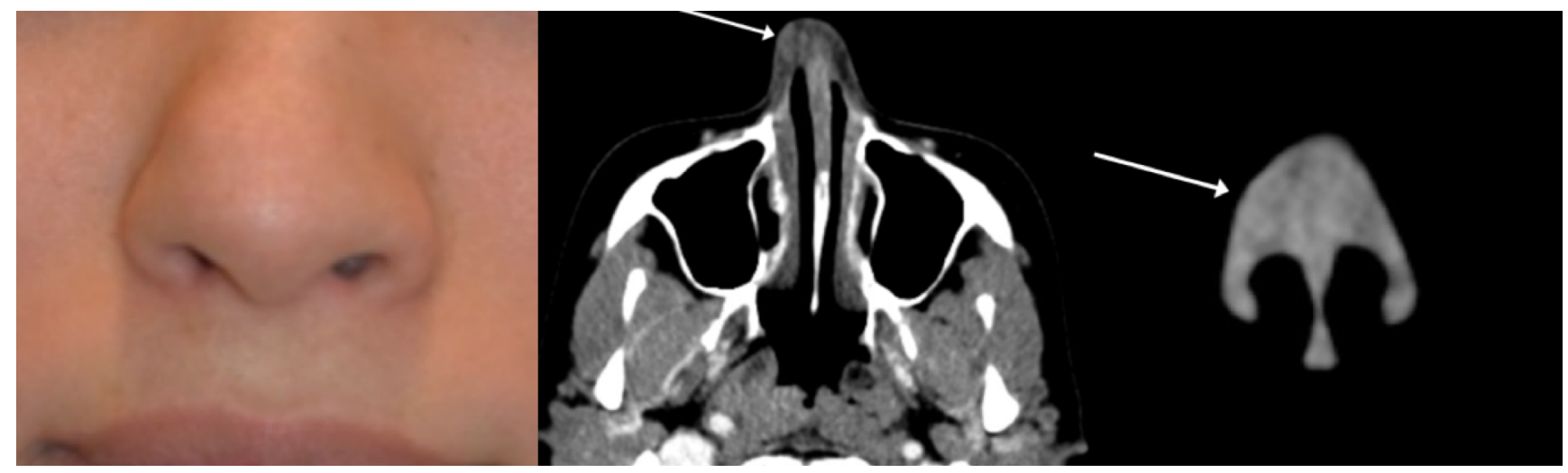

Figure 1: Preoperative photo showing a non-tender, subcutaneous, soft, smooth, raised, round mass in the right supratip region, measuring $8 \mathrm{~mm}$ in diameter (Left).

CT with IV contrast showing axial (middle) and coronal (right) images of the enhancing nodular nasal mass measuring 8 mm $\times 9 \mathrm{~mm} \times 4 \mathrm{~mm}(\mathrm{CC} \times \mathrm{AP} \times \mathrm{TR})$. The mass was situated over the right nasal cartilage without involvement of the nasal bones or sinuses.

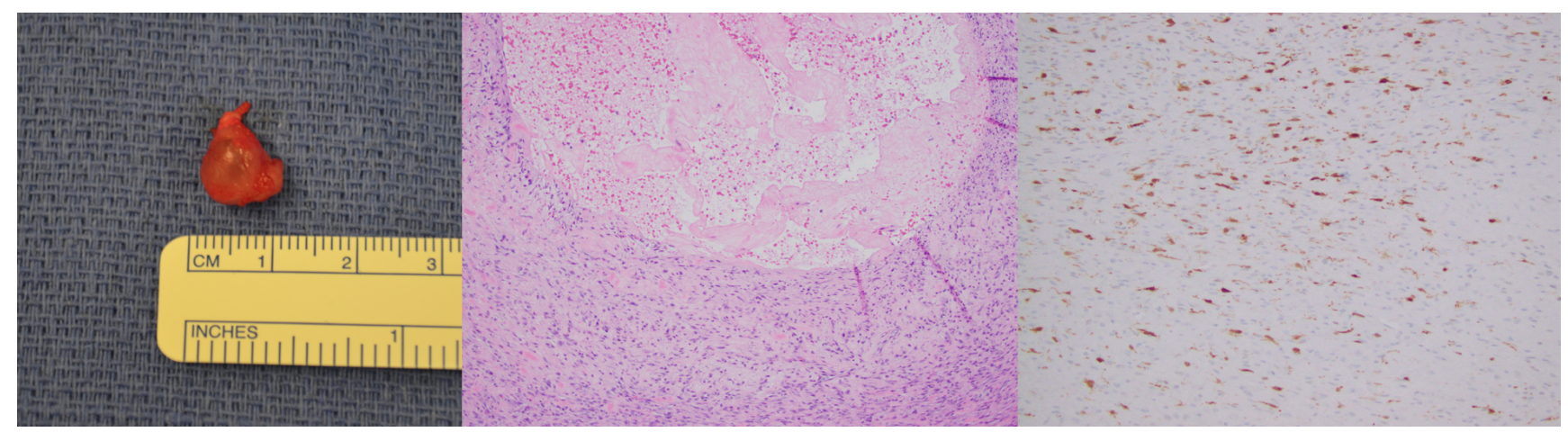

Figure 2: Left: Resected mass. Histological cross section of resected mass showing characteristic features of an aneurysmal fibrous histiocytoma.

Middle: A cystic space filled with blood products, amplification 10x).

Right: Immunohistochemistry: Factor XIIla (histiocyte marker), amplification 20x.

sharply separated (Figure 2).

Final pathology revealed a spindle cell lesion with cystic spaces with fibrin and blood contents, consistent with an aneurysmal fibrous histiocytoma (Figure 2). The tumor cells were partially and weakly positive for smooth muscle actin, factor XIIla, CD68; and negative for CD34, S- 100, Bcl-2, and cytokeratin AE1/AE3.

\section{Discussion}

Aneurysmal fibrous histiocytoma is a rare variant of the cutaneous fibrous histiocytoma with distinctive clinical and pathologic features. AFHs are confined to the dermis and have a cystic consistency, and are blue, black or dark red in appearance. They are generally $<1 \mathrm{~cm}$ in diameter and can quickly expand and change in color as blood extravasates into the tumor. In our patient, the typical dark red appearance could not be appreciated until after the nose was opened.

Any transcutaneous approach, including a Moh's excision, would have left a significant defect in the nasal tip. However, the open rhinoplasty approach allowed for optimum visualization while obviating the need for reconstruction after the mass was excised.

The patient had an excellent postoperative cosmetic result and has not had recurrence at two-year post-operatively.

\section{Conclusion}

We report the first case of nasal aneurysmal fibrous histiocytoma. The open rhinoplasty approach provided excellent exposure of the lesion intraoperatively and optimized postoperative cosmesis.

\section{References}

1. Calonje E, Fletcher CD (1995) Aneurysmal benign fibrous histiocytoma: Clinicopathological analysis of 40 cases of a tumour frequently misdiagnosed as a vascular neoplasm. Histopathology 26: 323-331.

2. McKenna DB, Kavanagh GM, McLaren KM, Tidman MJ (1999) Aneurysmal fibrous histiocytoma: An unusual variant of cutaneous fibrous histiocytoma. J Eur Acad Dermatol Venereol 12: 238-240.

3. Doyle LA, Fletcher CD (2013) Metastasizing "benign" cutaneous fibrous histiocytoma: A clinicopathologic analysis of 16 cases. Am J Surg Pathol 37: 484-495. 
4. Halim K, Karia PS, Schmults CD (2015) Aneurysmal dermatofibroma successfully treated with Mohs micrographic surgery. Dermatol Surg 41: 168-170.

5. Han TY, Chang HS, Lee JH, Lee WM, Son SJ (2011) A clinical and histopathological study of 122 cases of derma- tofibroma (benign fibrous histiocytoma). Ann Dermatol 23: 185-192.

6. Pierce CA, Konofaos P, Alvarez S, Wallace RD (2016) Excision and fat grafting of nasal tip dermoid cysts through an open rhinoplasty approach. J Craniofac Surg 27: e18-e20. 